\title{
Oral Immunization with F4 Fimbriae and CpG Formulated with Carboxymethyl Starch Enhances F4-Specific Mucosal Immune Response and Modulates Th1 and Th2 Cytokines in Weaned Pigs
}

\author{
Benjamin Delisle ${ }^{1}$, Carmen Calinescu ${ }^{2}$, Mircea Alexandru Mateescu ${ }^{2}$, John Morris Fairbrother ${ }^{1}$, Éric Nadeau ${ }^{1}$ \\ ${ }^{1}$ Reference Laboratory for Escherichia coli, Faculté de Médecine Vétérinaire, Université de Montréal, 3200 Sicotte, Saint- \\ Hyacinthe (Québec), Canada. \\ ${ }^{2}$ Department of Chemistry and Centre BioMed, Université du Québec à Montréal, CP 8888, Succursale A, Montréal \\ (Québec), Canada.
}

Received, September 9, 2012; Revised, October 31, 2012; Accepted, November 22, 2012; Published, November $27,2012$.

\begin{abstract}
Purpose. F4 fimbriae are a potential candidate for an oral subunit vaccine for prevention of postweaning diarrhea in swine due to infection with F4-positive enterotoxigenic Escherichia coli. However, large quantities of F4 fimbriae are required to induce a specific antibody response. The aim of the present study was to evaluate the effect of supplementation of F4 fimbriae with Cytosine-phosphate-Guanosineoligodeoxynucleotide (CpG-A D19) or with complete cholera toxin (CT) as adjuvants on the F4-specific antibody response and cytokine production in weaned pigs following oral administration of $\mathrm{F} 4$ fimbrial antigen formulated with Carboxymethyl Starch (CMS). Methods. Oral dosage forms of F4 fimbriae alone or supplemented with CpG-A D19 or with CT were formulated with CMS as monolithic tablets, obtained by direct compression, and administered to weaned pigs. Blood and faecal samples were collected to determine the systemic and mucosal immune status of animals at various times until necropsy. During necropsy, contents of the jejunum and ileum were collected for determination of mucosal F4 specific antibodies. Segments of jejunum and ileum were also used to measure mRNA cytokine production. Results. The presence of $\mathrm{CpG}$ in the formulation of the fimbriae significantly increased F4-specific immunoglobulin (Ig) IgM and IgG levels in intestinal secretions, and enhanced Th1 (Interferon-gamma / IFN- $\gamma$, Tumour Necrosis Factor-alpha / TNF- $\alpha$, Interleukin-12p40 / IL-12p40, IL-1 $\beta$ ) and Th2 (IL-4, IL-6) cytokine production in intestinal tissues. Supplementation with CT did not result in induction of F4-specific antibodies in secretions, although a significant Th1 response (IFN- $\alpha$, IFN- $\gamma$, IL-18) was detected in tissues. Neither F4-specific systemic antibodies, nor intestinally secreted IgA were detected throughout the immunization trial for all groups. Conclusions. CpGA D19 appeared to be a promising adjuvant for an oral F4 subunit vaccine formulated with CMS excipient as monolithic tablets. This matrix afforded gastro-protection and delivered the F4 fimbriae at their intestinal sites.
\end{abstract}

This article is open to POST-PUBLICATION REVIEW. Registered readers (see "For Readers") may comment by clicking on ABSTRACT on the issue's contents page.

\section{INTRODUCTION}

F4-positive enterotoxigenic Escherichia coli (ETEC:F4) infections represent a major cause of post-weaning diarrhea (PWD) in pigs. PWD has a significant mortality rate and most often results in reduced gain of weight in pigs, leading to significant economic losses in swine production (1). F4 fimbriae are proteinaceous surface antigens composed of repeated subunits (2). They mediate bacterial binding to F4-specific receptors (F4R) located on the brush border of small intestinal enterocytes and subsequent colonization of the small intestine. Several antimicrobial agents are often used to control PWD. However, increasing bacterial resistance to antibiotics underlines the need for new approaches. Oral vaccination is a promising alternative for the control of this disease. Advantages include a strong acquired mucosal immune response to administered antigen, easier administration procedures, reduced side effects and

\footnotetext{
Corresponding Author: John Morris Fairbrother, Reference Laboratory for Escherichia coli, Faculté de Médecine Vétérinaire, Université de Montréal, 3200 Sicotte, SaintHyacinthe (Québec), Canada, E-mail Address: john.morris.fairbrother@umontreal.ca
} 
more convenient conditions of production (3).

F4 fimbriae have been proposed as a potential candidate for an oral subunit vaccine, due to their role in bacterial adherence and because they elicit a rapid and strong host immune response (4). Van den Broeck et al. (5-7) demonstrated that oral immunization of weaned pigs with $\mathrm{F} 4$ fimbriae induced systemic F4-specific antibody responses and F4-specific antibody secreting cells in intestinal tissues. However, the proposed immunization procedure required large quantities of $\mathrm{F} 4$, this antigen not being protected against degradation by the low $\mathrm{pH}$ of the stomach and by the presence of digestive enzymes. This disadvantage may be overcome by incorporating the F4 into a delivery system able to protect the antigen during gastric transit and to deliver it to the specific intestinal sites of F4-specific antibody response (8). The potential of carboxymethyl high amylose starch excipient (CMS) as delivery system for fimbriae has already been shown in vitro (9). The protection of F4 fimbriae provided by the biodegradable CMS matrix could offer a more effective piglet vaccination. Due to its functionality dependant of $\mathrm{pH}, \mathrm{CMS}$ is an excipient able to afford gastroprotection of bioactive agents (9-10).

The amount of fimbriae required to stimulate an adequate oral immune response (5) may also be reduced by supplementation with an adjuvant to boost the immune response. Cholera toxin (CT), a potent immunostimulating adjuvant, has been used in several oral vaccines (11-13). It is a multimeric protein composed of $\mathrm{A}$ and $\mathrm{B}$ subunits. The $\mathrm{B}$ subunits bind the monosialogangliosides present on the surface of mammalian epithelial and hematopoietic cells, whereas the A subunits enter the cytosol and activate ADP-ribosylation of $G$ protein, causing the elevation of cyclic AMP (14). Cytosine-phosphate-Guanosine-

Oligodeoxynucleotides (CpG-ODNs) are another potent class of immunomodulators for mucosal adjuvants in vaccines (15). CpGs interact with pattern recognition receptors on immune cells and are recognized as danger signals that lead to the stimulation of the innate and adaptive host immune defence system. The CpG-A D19 stimulated the in vitro proliferation of peripheral blood mononuclear cells (PBMC) with a higher production of Interleukin-6 (IL-6), IL-12 and Tumour Necrosis Factor-alpha / TNF- $\alpha$ (16), and an increased level of Interferon-gamma / INF- $\gamma$ (17). Although $\mathrm{CpG}$
type-A is usually associated with the stimulation of Th1 cells by production of high levels of IFN- $\alpha$ (18), Van der Stede et al. (19) showed in vitro that CpG-A D19 can also stimulate B-cell proliferation and enhance expression of the major histocompatibility complex II (MHC II). They also found that intramuscular administration of $\mathrm{F} 4$ fimbriae and CpG-A D19 in pigs enhanced F4specific proliferation of PBMC (20). Recently, Zhang et al. (21) demonstrated that subcutaneous administration of a CpG-A D19 equivalent, containing multiple $\mathrm{CpG}$ motifs, stimulated the innate immune system in weaned pigs. To date, the adaptive response and intestinal cytokine production in pigs following oral administration of CpG-A D19 with F4 fimbriae, has not been described. The aim of the present study was to orally administrate the F4 fimbrial antigen formulated with CMS excipient as monolithic tablets and to evaluate the effect of supplementation of F4 fimbriae with CpG-A D19 or CT on the F4specific antibody response and cytokine production in weaned pigs. The novelty of our work is the finding that F4 fimbriae in the presence of $\mathrm{CpG}$ adjuvant, both formulated with CMS excipient (monolithic tablets), could be an effective oral subunit vaccine.

\section{MATERIALS AND METHODS}

\section{Purification of F4 fimbriae}

F4 fimbriae were purified as previously described (22), with some modifications. Briefly, the F4positive bacterial suspension was centrifuged at $7000 \mathrm{rpm}$ for $15 \mathrm{~min}$, and the pellet was left to stand overnight at $4^{\circ} \mathrm{C}$. The pellet was homogenized twice for $5 \mathrm{~min}$ on ice at maximum speed using an X-120 homogenizer (Polyscience, Staufen, Germany), with a 5 min cooling period on ice between each homogenization. The homogenate was then centrifuged at $11000 \mathrm{rpm}$ for $20 \mathrm{~min}$ and the supernatant was precipitated with $20 \%$ ammonium sulphate for 16 to $18 \mathrm{~h}$ at $4{ }^{\circ} \mathrm{C}$ under agitation. The suspension was then centrifuged at $10000 \mathrm{rpm}$ for $1 \mathrm{~h}$. The pellet containing the fimbriae was dissolved in a Phosphate Buffer Saline (PBS, $10 \mathrm{mM}, \mathrm{pH}$ 7.0) and dialyzed against water for $7 \mathrm{~h}$, then against PBS, for 16 to $18 \mathrm{~h}$. The suspension was adjusted to $\mathrm{pH} 4.0$ with $2.5 \%$ citric acid, agitated for $2 \mathrm{~h}$ at $4{ }^{\circ} \mathrm{C}$, and centrifuged at $11000 \mathrm{rpm}$ for $15 \mathrm{~min}$. Finally, the pellet containing 
the fimbriae was lyophilized. The protein concentration of the semi-purified fimbrial preparation was determined by the modified Lowry method (23) and the purity was assessed by sodium dodecyl sulphate polyacrylamide gel electrophoresis (SDS-PAGE) on $12 \%$ polyacrylamide gels.

\section{Synthesis of CMS polymeric excipient}

The CMS excipient was synthesized by etherification of high amylose starch (Hylon VII) with monochloroacetic acid in an alkaline reaction medium, as previously described by Calinescu et al. (9). $70 \mathrm{~g}$ Hylon VII were suspended in $170 \mathrm{~mL}$ of distilled water and warmed at $50^{\circ} \mathrm{C}$ under continuous stirring. Then, a volume of $235 \mathrm{~mL}$ of an aqueous $1.45 \mathrm{M} \mathrm{NaOH}$ solution was added to the reaction medium for starch gelatinisation $(20 \mathrm{~min}$, $50^{\circ} \mathrm{C}$ ). To favour the carboxymethylation (nucleophilic substitution), $55 \mathrm{~mL}$ of $10 \mathrm{M} \mathrm{NaOH}$ solution were added to the reactional medium to transform the starch into a more reactive alkoxide form. $45.5 \mathrm{~g}$ of monochloroacetic acid, freshly dissolved in a minimal volume of water, were then added to the medium, and the reaction was carried on for $1 \mathrm{~h}$ at $50{ }^{\circ} \mathrm{C}$ under continuous stirring. After the substitution step, the gel-slurry was neutralized with an acetic acid solution, and finally, it was precipitated with acetone. At the end of this procedure, the polymeric derivative was washed with acetone:water $(60: 40, v / v)$ and filtrated for several times. The final drying was realized with pure acetone. CMS was then filtrated, and the obtained powder was air exposed at room temperature for drying, and sieved to obtain a powder with particles granulometrically smaller than $300 \mu \mathrm{m}$. This powder was used to prepare the monolithic tablets. The degree of substitution of CMS was determined by direct titration with $0.1 \mathrm{M}$ $\mathrm{NaOH}$ solution, as previously described (10).

\section{F4 fimbriae vaccine preparations}

Lyophilised F4 fimbriae were exposed to 5 kGray (kGy) gamma-irradiation from Cobalt 60 to eliminate live $\mathrm{F}^{+}$bacteria surviving the purification process. Sterility of the irradiated F4 preparation was confirmed by absence of bacterial growth on blood agar and Luria-Bertani broth following inoculation of irradiated fimbriae. In addition, the integrity of the irradiated fimbriae was confirmed by SDS-PAGE and western blot, and with an indirect immunofluorescence adhesion test using intestinal sections of previously identified F4Rpositive pigs (24).

Fabrication of CMS monolithic tablets containing fimbriae and adjuvant

Irradiated lyophilized F4 fimbriae, alone or with complete CT (Sigma, St-Louis, USA) or with CpGA D19 (5'-ggTGCATCGATGCAGggggg-3', BioCorp $^{\circledR}$ AND inc., Montreal, Canada) were incorporated into $200 \mathrm{mg}$ monolithic tablets formulated with CMS excipient. Thus, four different CMS formulations were obtained: (1) Formulation without F4 fimbriae and adjuvant (unvaccinated control group), (2) Formulation with $500 \mu \mathrm{g}$ F4 fimbriae/dosage form (tablet) without adjuvant (F4 group), (3) Formulation with $500 \mu \mathrm{g}$ F4 fimbriae associated with $25 \mu \mathrm{g}$ complete CT adjuvant/tablet (F4-CT group) and (4) Formulation with $500 \mu \mathrm{g}$ F4 fimbriae associated with $50 \mu \mathrm{g}$ CpG-A D19 adjuvant/tablet (F4-CpG group). The tablets $(200 \mathrm{mg})$ used for vaccination of piglets were obtained by direct compression at $2.5 \mathrm{~T}$ (Carver press, Wabash, IN, USA) of powders containing the F4 fimbriae bioactive agent, with or without $\mathrm{CT}$ or $\mathrm{CpG}$ adjuvant, and CMS excipient. For the unvaccinated control group, the monolithic tablets were obtained by direct compression $(2.5 \mathrm{~T})$ of $200 \mathrm{mg}$ CMS excipient only.

\section{Determination of F4R-positive piglets}

To identify F4R-positive pigs to be included in the immunization assays, blood was collected from 2 weeks old nursing piglets in tubes containing EDTA $(1.8 \mathrm{mg} / \mathrm{mL}, 7 \mathrm{~mL})$ as anti-coagulant. Complete DNA genome was extracted from whole blood using a Qiamp DNA mini-kit (Qiagen Inc, Mississauga, Canada) and analyzed by a Polymerase Chain Reaction - Restriction Fragment Length Polymorphism (PCR-RFLP) assay as described by Jensen et al. (25).

\section{Animal housing and necropsies}

Pigs were handled throughout the study in accordance with the guidelines of the Canadian Council for Animal Care. Approval to carry out this in vivo study was obtained from the Institutional Animal Ethics Committee of the Faculty of Veterinary Medicine (Université de Montréal, Québec, Canada). 
A total of 22 F4R-positive piglets (Landrace $X$ Duroc) were selected and weaned at 28 days of age. Upon arrival in the animal care facilities, all pigs were treated orally with $150000 \mathrm{U} / \mathrm{Kg}$ body weight/day colistin (Pharmacie D. Bond and F. Beaulac, Actonvale, Canada) for 5 days to control the ETEC strains potentially present in the intestinal microflora. After 2 days of treatment, the pigs were transferred into isolation units. The presence of F4positive ETEC in faecal swabs from the pigs was determined by PCR on arrival and subsequently at three day intervals. Animals were weighed and separated into 3 vaccinated groups of 5 pigs/group and one unvaccinated group of 7 animals. Food and water were administered to the pigs ad libitum. Blood and faecal samples were collected to determine the systemic and mucosal immune status of animals at the end of the colistin treatment, prior to the initial immunization (day 0), and at various times until necropsy (26 days post-initial immunization). Prior to necropsy, pigs were tranquillized with a mixture of $10 \mathrm{mg}$ ketamine hydrochloride (Biomeda-MTC, Cambridge, Canada) and $20 \mathrm{mg}$ xylazine (Bayer, Toronto, Canada) per $\mathrm{kg}$ of body weight and euthanized by intravenous injection of $108 \mathrm{mg}$ per $\mathrm{kg}$ of body weight of sodium pentobarbital (Biomeda-MTC, Cambridge, Canada). During necropsy, contents of the jejunum and ileum were collected in $50 \mathrm{~mL}$ tubes, kept on ice, and then stored at $-80^{\circ} \mathrm{C}$ until determination of mucosal F4-specific antibodies. Segments of jejunum and ileum $(1 \times 2 \mathrm{~cm})$ with $(\mathrm{PP}+)$ or without (PP-) Peyer's patches (PP) were sampled to measure mRNA cytokine production. All tissue samples were placed in cryotubes, snapfrozen in liquid nitrogen, and stored at $-80^{\circ} \mathrm{C}$. In addition, $3 \mathrm{~mm}$ transversal sections of jejunum were embedded in an optimal cutting temperature Sakura Tissue-Tek $^{\circledR} \quad$ O.C.T. compound (Somagen Diagnostics, Edmonton, Canada), snap-frozen in liquid nitrogen, and stored at $-80{ }^{\circ} \mathrm{C}$ until testing to confirm the F4-receptor (F4R) status of animals using an F4 indirect immunofluorescence assay (24).

\section{Immunization procedure}

All pigs were orally immunized twice. Each immunization consisted of administration of one pill (placebo or containing F4 fimbriae with and without adjuvant) per day for 3 successive days. The initial immunization (day 1) started in pigs of
35 days of age and the second immunization started on day 14 post-initial immunization.

\section{Detection of F4-specific antibodies Sample preparation}

Serum

Blood was taken from the jugular vein on the day prior to the initial immunization and at 5, 8, 13, 16, 20, 23 and 26 days post-initial immunization, kept on ice, and then centrifuged to obtain serum that was then stored at $-20{ }^{\circ} \mathrm{C}$ until analysis was carried out.

\section{Intestinal contents}

At 26 days post-initial immunization, the animals were euthanized and a necropsy was performed. The intestinal contents were collected from the jejunum and ileum and stored at $-80^{\circ} \mathrm{C}$ until processing as described by Wenneras et al. (26), with slight modifications. Briefly, collected intestinal contents were treated by addition of 100 $\mu \mathrm{g} / \mathrm{mL}$ (final concentration) soybean trypsin inhibitor (Sigma, St. Louis, USA) and 0.05 M (final concentration) EDTA (Sigma, St. Louis, USA) and kept on ice for $15 \mathrm{~min}$. Then, the samples were centrifuged at $1000 \mathrm{x} \mathrm{g}$ for $15 \mathrm{~min}$, and the supernatant of each sample was treated by adding 2 $\mathrm{mM}$ (final concentration) phenylmethylsulfonyl fluoride (Sigma, St. Louis, USA) and left to stand at room temperature for $15 \mathrm{~min}$. Bovine serum albumin (Sigma) and sodium azide (Sigma) were then added to final concentrations of $1 \mathrm{mg} / \mathrm{mL}$ and $0.02 \%(\mathrm{w} / \mathrm{v})$, respectively. The intestinal contents were freeze-dried and reconstituted with PBS (1:20) before analysis by ELISA.

\section{Detection of F4-specific antibodies by ELISA}

Systemic and secreted intestinal F4-specific antibodies were detected using an indirect ELISA test. The wells of the microtitre plates (Nalge Nunc, VWR International Co., Mississauga, Canada) were coated overnight at $4{ }^{\circ} \mathrm{C}$ with $\mathrm{F} 4$ fimbriae $(5 \mu \mathrm{g} / \mathrm{mL}$ in $0.1 \mathrm{M}$ carbonate buffer, $\mathrm{pH} 9.4$ ) and non-specific binding sites were blocked by PBS supplemented with $0.2 \%$ Tween-80 $(v / v)$. Samples of serum and intestinal contents were first diluted with PBS (1:10 dilution for serum and 1:20 dilution for intestinal contents), then two fold-serial dilutions were performed in PBS containing $0.2 \%$ Tween-20 $(v / v)$ and $3 \%$ bovine serum albumin $(w / v)$. Microtiter plates were then incubated for $1 \mathrm{~h}$ at $37^{\circ} \mathrm{C}$. Optimal 
dilutions (1:2500 for each conjugate) of goat antiswine $\operatorname{IgM}, \operatorname{IgG}$ or $\operatorname{IgA}$ horseradish peroxidase conjugates (Bethyl Laboratories, Cedarlane Laboratories Ltd., Burlington, Canada) were added to the wells and the microtiter plates were incubated for $1 \mathrm{~h}$ at $37{ }^{\circ} \mathrm{C}$. Then, the 2,2'-azino-bis(3ethylbenzothiazoline-6-sulfonic acid) substrate was added, and the optical density (OD) was measured at $405 \mathrm{~nm}$ after an incubation of $15 \mathrm{~min}$ at $37^{\circ} \mathrm{C}$. Between the incubation steps, the plates were washed three times with PBS containing $0.2 \%$ Tween-20 $(v / v)$. The cut-off values, being the mean OD at day 0 plus 2 times the standard deviation, were 0.32 for F4-specific IgM and IgG and 0.30 for IgA. The antibody titre was the inverse of the highest dilution which still had an OD higher than the cut-off value. When the titre was below the detection limit, it was arbitrarily set to the $\log _{10}$ of one-half the detection limit for display purposes and mean calculation (27).

\section{Porcine cytokine semi-quantitative reverse transcription polymerase chain reaction (Reverse Transcription-PCR)}

Reverse Transcription-PCR was used to measure semi-quantitatively mRNA production for 10 cytokines (IFN- $\alpha$, IFN- $\gamma$, TNF- $\alpha$, IL-6, IL-10, IL$1 \beta$, IL-4, IL-12p40, IL-18 and IL-8) in tissues. Approximately $50 \mathrm{mg}$ of frozen tissue was immediately placed in liquid nitrogen to obtain a dry powder using a mortar and a pestle. Then, the tissue homogenate was transferred into a tube containing $1 \mathrm{~mL}$ of Trizol (Invitrogen, Burlington, Canada), and the extraction was carried out as described by the manufacturer. The RNA pellet was then resuspended in $25 \mu \mathrm{L}$ Promega nuclease-free water (Fisher Scientific Ltd., Ottawa, Canada) and heated at $65^{\circ} \mathrm{C}$ for $10 \mathrm{~min}$. Samples were treated with Turbo DNase (Ambion/Applied Biosystems Canada, Streetsville, Canada) according to the manufacturer's protocol, followed by precipitation using a solution of $10 \%$ sodium acetate. RNA samples were resuspended in nuclease-free water to obtain approximately $300 \mathrm{ng} / \mu \mathrm{L}$ of RNA. Reverse transcription was carried out using approximately 1 $\mu \mathrm{g}$ of total RNA and primed by random hexamer priming (Roche Diagnostics, Laval, Canada). Other reagents for reverse transcription, including RNase inhibitor, dNTP and SuperScript II RT (Invitrogen, Burlington, Canada), were used according to the manufacturer's instructions. At the end of the reverse transcription, residual RNA was eliminated by adding $2 \mathrm{U}$ of RNase $\mathrm{H}$ (Epicentre Biotechnologies, WI, USA), and the sample volume was adjusted to $100 \mu \mathrm{L}$ with nuclease-free water. PCR was carried out using Biotools Taq enzymes (Biotools B\&M Labs., Madrid, Spain), PCR buffer (10 mM Tris-HCl, pH 9.0), $1.5 \mathrm{mM} \mathrm{MgCl} 2,10 \mathrm{mM}$ dNTP, 100 pmol of sense and anti-sense primers for each cytokine, 2.5 U Taq DNA polymerase, and 10 $\mu \mathrm{L}$ of sample cDNA template in a $50 \mu \mathrm{L}$ reaction volume. RT-PCR and PCR were performed in a Biometra thermocycler (Gottingen, Germany) using the same primers and conditions similar to those described previously for IL-1 $\beta$, IL-4, IL-6, IL-8, IL10 , TNF- $\alpha$, IFN- $\gamma$, cyclophilin (28), IL-12p40 (29), IL-18 (30) and IFN- $\alpha$ (31). An aliquot of each PCR sample was migrated on a $1.8 \%$ Tris-Borate EDTA-agarose gel. The gels were stained with ethidium bromide and photographed using an alphaimager (Alpha Innotech, San Leandro, USA). The relative amount of each product was determined by measuring the density of the band using BioNumerics software (Applied-maths Inc., Austin, USA). For each cytokine, the amount of the RTPCR product was normalized to the value of cyclophilin, a constitutively expressed housekeeping gene used as standard for each sample.

\section{STATISTICS}

Differences between groups in antibody production and in cytokine mRNA expression ratio for combined results of jejunum and ileum were analyzed for statistical significance with the General Linear Model (Repeated Measures Analysis of Variance) test, and considered as duplicate sampling for statistical analysis.

\section{RESULTS}

CpG enhances the production of mucosal specific anti-F4 IgM in the small intestine

Upon necropsy of the pigs (26 days after initial immunization), we observed a significant increase $(\mathrm{P}=0.01)$ in the mucosal anti-F4 IgM titre in small intestinal contents of the F4-CpG group compared to that of the unvaccinated or the F4 group (Figure $1)$. 


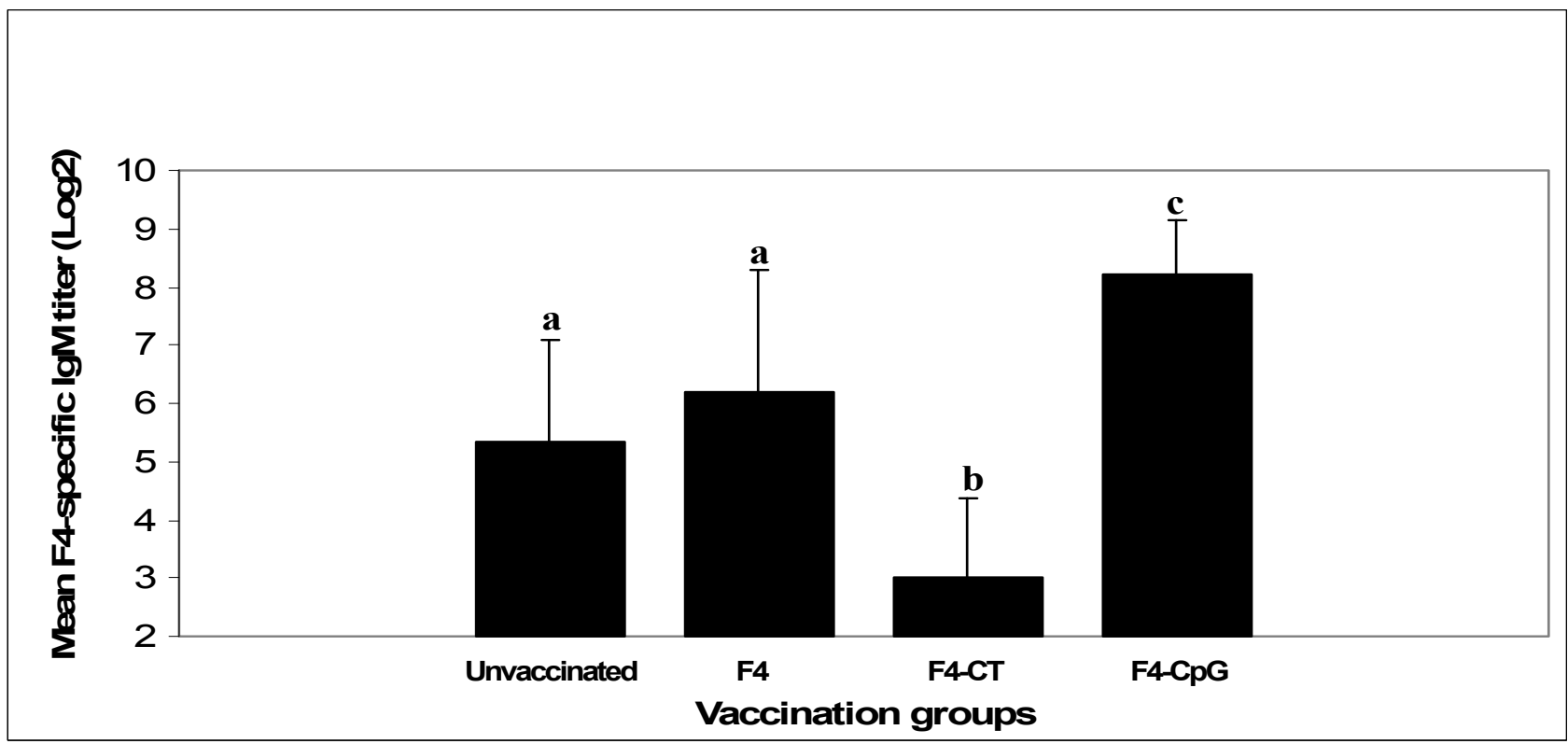

Figure 1. Modulation of specific anti-F4 IgM mucosal antibody by cholera toxin and CpG adjuvants after oral administration of F4 fimbriae formulated with carboxymethyl high amylose starch (CMS). Unvaccinated group: CMS monolithic tablets $(200 \mathrm{mg})$. Vaccinated groups: CMS monolithic tablets $(200 \mathrm{mg})$ containing $500 \mu \mathrm{g}$ F4 fimbriae (F4 group), $500 \mu \mathrm{g}$ F4 fimbriae and $25 \mu \mathrm{g}$ complete cholera toxin (F4-CT group), $500 \mu \mathrm{g}$ F4 fimbriae and $50 \mu \mathrm{g}$ Cytosinephosphate-Guanosine-Oligodeoxynucleotide ( $\mathrm{F} 4-\mathrm{CpG}$ group). Letters a, b and c represent significantly different $(\mathrm{P} \leq 0.05)$ groups ( $\mathrm{n}=5 \mathrm{pigs} /$ group for vaccinated groups and $\mathrm{n}=7 \mathrm{pigs} /$ group for unvaccinated group). Degree of substitution of CMS: 0.157 .

In contrast, the mucosal anti-F4 IgM titre in the intestinal contents of the F4-CT group was significantly lower $(\mathrm{P}=0.0004)$ than that of the $\mathrm{F} 4$ group. No significant increase in the level of anti-F4 IgM was observed in the small intestinal contents of pigs of the F4 group compared to that of the unvaccinated group.

\section{Production of mucosal specific anti-F4 IgG in the small intestine}

In the intestinal contents, a significant increase $(\mathrm{P}=0.04)$ in the anti-F4 IgG titre was observed for the F4 group, compared to that of the unvaccinated group (Figure 2). Also, the anti-F4 IgG titre for the F4-CpG group was significantly higher $(\mathrm{P}=0.0004)$ than for the unvaccinated or the F4 groups, whereas the anti-F4 IgG titre for the F4-CT group was significantly lower $(\mathrm{P}=0.002)$ than for the $\mathrm{F} 4$ group. Mucosal anti-F4 IgA was not detected in the intestinal contents of any group.

\section{Absence of serum F4-specific antibody after oral immunization of pigs}

No significant difference in specific serum anti-F4 IgM response was observed between the vaccinated
(F4, F4-CpG, or F4-CT) and unvaccinated groups up to 26 days after initial oral immunization (Figure 3). Similarly, no significant difference in specific serum anti-F4 IgA response was observed between the vaccinated and unvaccinated groups (data not shown).

The serum anti-F4 IgG titres were not determined because pigs originated from commercial farms where sows are immunized with a commercial vaccine containing F4 fimbriae for the prevention diarrhea due to ETEC-F4 in newborn piglets. Commonly used commercially available vaccines are given parenterally and may be killed whole cell bacterins or purified fimbrial vaccines. This vaccination results in the production of high levels of specific IgG which is transferred to the piglets via the colostrum. This resulted in a high serum anti-F4 IgG antibody level in all animals before the vaccination procedure started, preventing the setting up of a realistic cut-off value for specific anti-F4 IgG. 


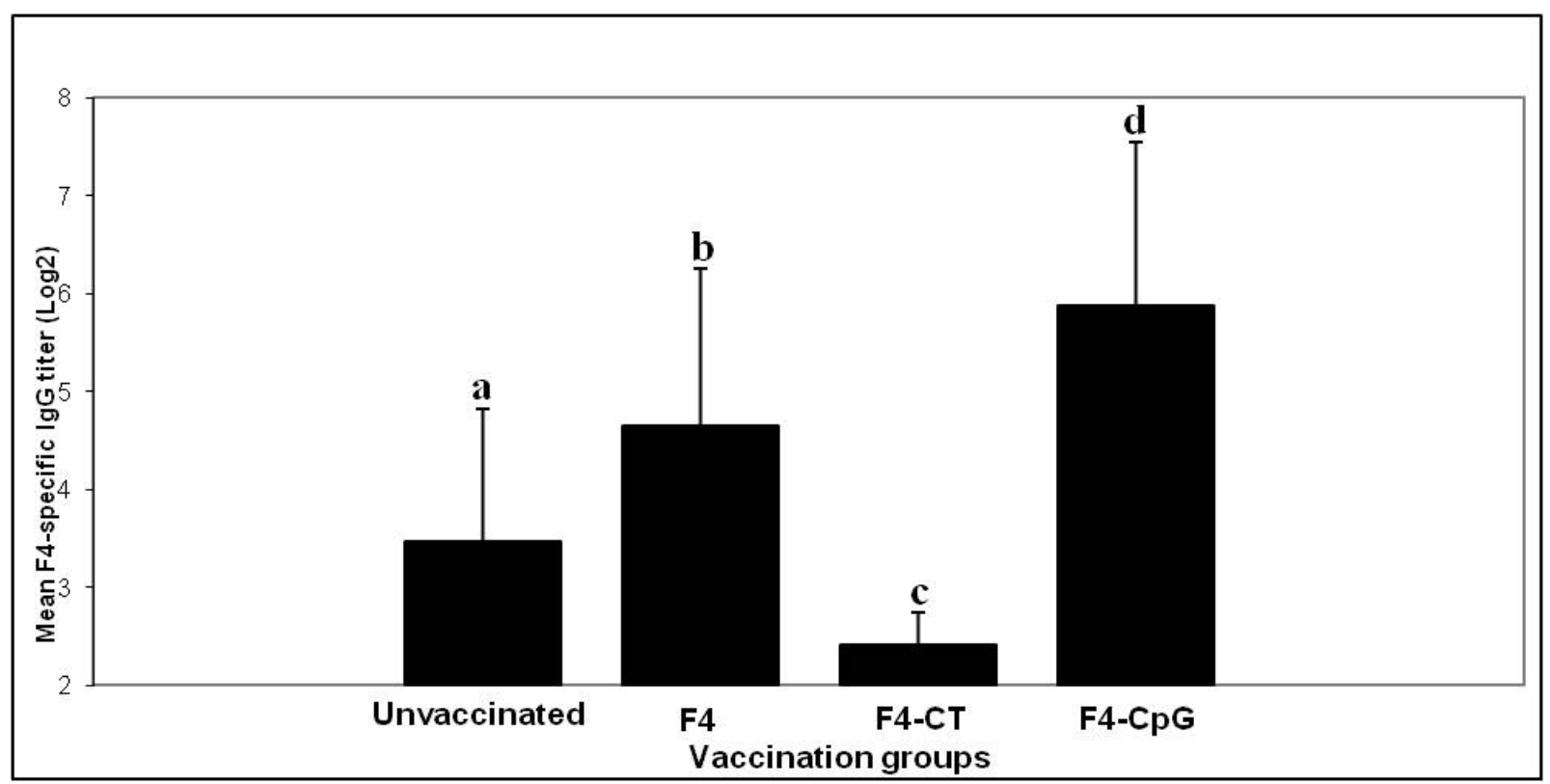

Figure 2. Modulation of specific anti-F4 IgG mucosal antibody by cholera toxin and CpG adjuvants after oral administration of F4 fimbriae formulated with carboxymethyl high amylose starch (CMS) Unvaccinated group: CMS monolithic tablets $(200 \mathrm{mg})$. Vaccinated groups: CMS monolithic tablets $(200 \mathrm{mg})$ containing $500 \mu \mathrm{g}$ F4 fimbriae (F4 group), $500 \mu \mathrm{g} \mathrm{F} 4$ fimbriae and $25 \mu \mathrm{g}$ complete cholera toxin (F4-CT group), $500 \mu \mathrm{g}$ F4 fimbriae and $50 \mu \mathrm{g}$ Cytosinephosphate-Guanosine-Oligodeoxynucleotide (F4-CpG group). Letters a, b, c, and d represent significantly different $(P \leq 0.05)$ groups ( $n=5$ pigs/group for vaccinated groups and $n=7$ pigs/group for unvaccinated group). Degree of substitution of CMS: 0.157 .

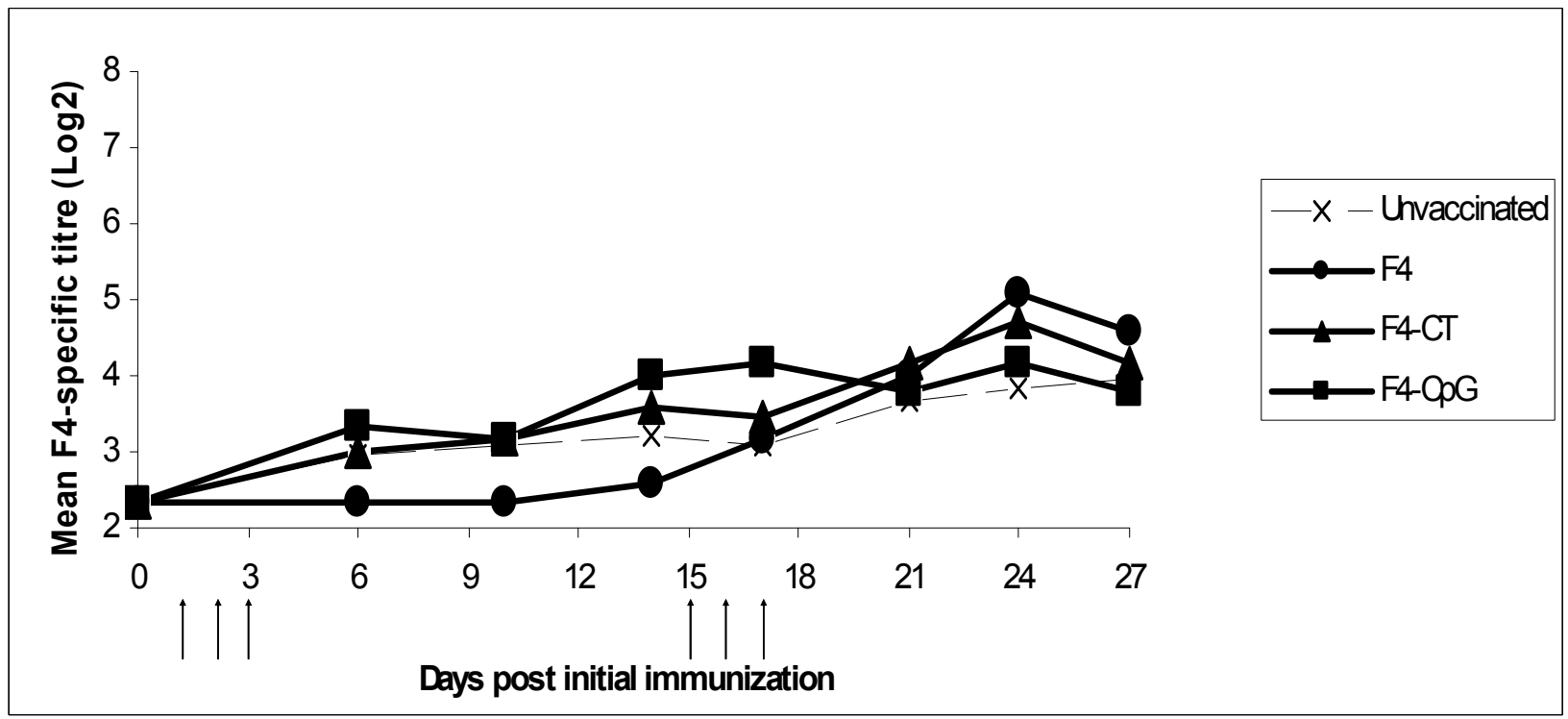

Figure 3. Levels of anti-F4 IgM serum antibody following oral administration of F4 fimbriae formulated with carboxymethyl high amylose starch (CMS). Unvaccinated group: CMS monolithic tablets (200 mg). Vaccinated groups: CMS monolithic tablets $(200 \mathrm{mg}$ ) containing $500 \mu \mathrm{g}$ F4 fimbriae (F4 group), $500 \mu \mathrm{g} \mathrm{F} 4$ fimbriae and $25 \mu \mathrm{g}$ complete cholera toxin (F4-CT group), $500 \mu \mathrm{g}$ F4 fimbriae and $50 \mu \mathrm{g}$ Cytosine-phosphate-Guanosine-Oligodeoxynucleotide (F4CpG group). No significant difference in mean F4-specific IgM serum antibody titres was observed between the F4, F4-CT, F4-CpG and unvaccinated groups ( $\mathrm{n}=5$ pigs/group for vaccinated groups and $\mathrm{n}=7$ pigs/group for unvaccinated group). Degree of substitution of CMS: 0.157 . Arrows indicate consecutive days of the homologous oral immunization procedure (see materials and methods). Day 1: initial immunization, Day 26: necropsy. 
CpG and CT up-regulate cytokine mRNA in different tissues

Cytokine mRNA expression in PP-negative (PP-) and $\mathrm{PP}$-positive $(\mathrm{PP}+)$ intestinal tissues following necropsy at 26 days post-initial immunization was examined in order to explore the mechanisms for the observed modulation of specific mucosal antibody response to F4 fimbriae. No significant difference in expression of cytokines was observed between the F4 and unvaccinated groups, for either $\mathrm{PP}+$ or PP- tissues. However, a significantly greater expression of IFN- $\gamma$ and IL- 4 was observed for the F4-CpG group than for the F4 group, in both the $\mathrm{PP}-$ and PP+ tissues (Table 1). Other Th1 and Th2 cytokines, such as IL12p40, TNF- $\alpha$ and IL-6 in the
PP- tissues and IL- $1 \beta$ in the PP+ tissues, were also significantly up-regulated for the $\mathrm{F} 4-\mathrm{CpG}$ group. For the F4-CT group, significantly up-regulated pro-inflammatory cytokines were: IFN- $\gamma$ in PP- and $\mathrm{PP}+$ tissues and IFN- $\alpha$ and IL-18 in PP- tissues (Table 1). Overall, cytokine mRNA expression was higher in PP+ than in PP- tissues for IL-6, IL-10, IL-12 and TNF- $\alpha$ (Figure 4). The mRNA for IL-8 cytokine was highly expressed in a constitutive manner, with small differences between groups with or without adjuvant, in all tissues analyzed at 26 days after initial immunization (data not shown). In all groups and tissues, the cyclophilin housekeeping gene was expressed at a similar level.

Table 1. Up-regulation of cytokine mRNA expression in intestinal tissues of pigs immunized with F4 fimbriae in the presence of $\mathrm{CpG}$ or CT

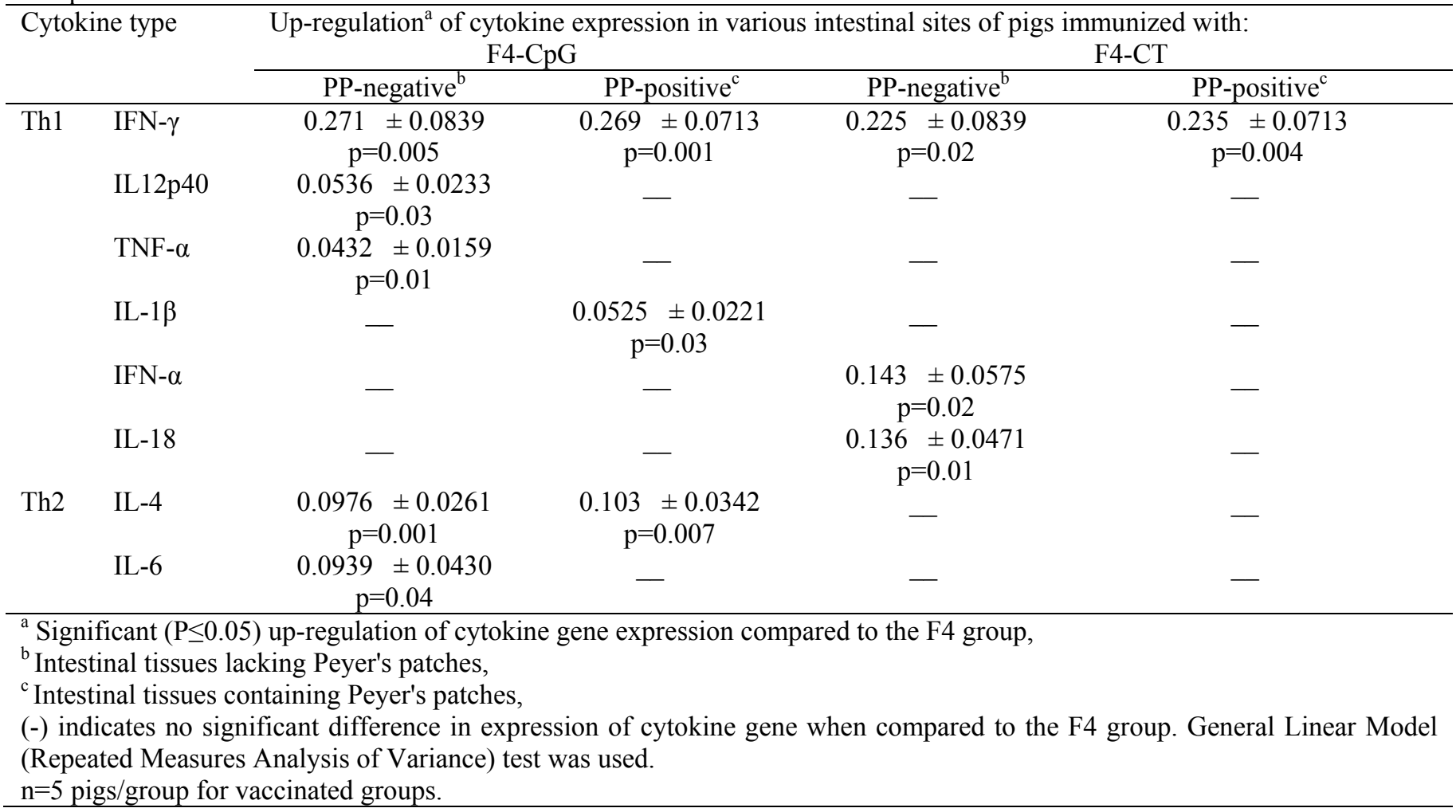



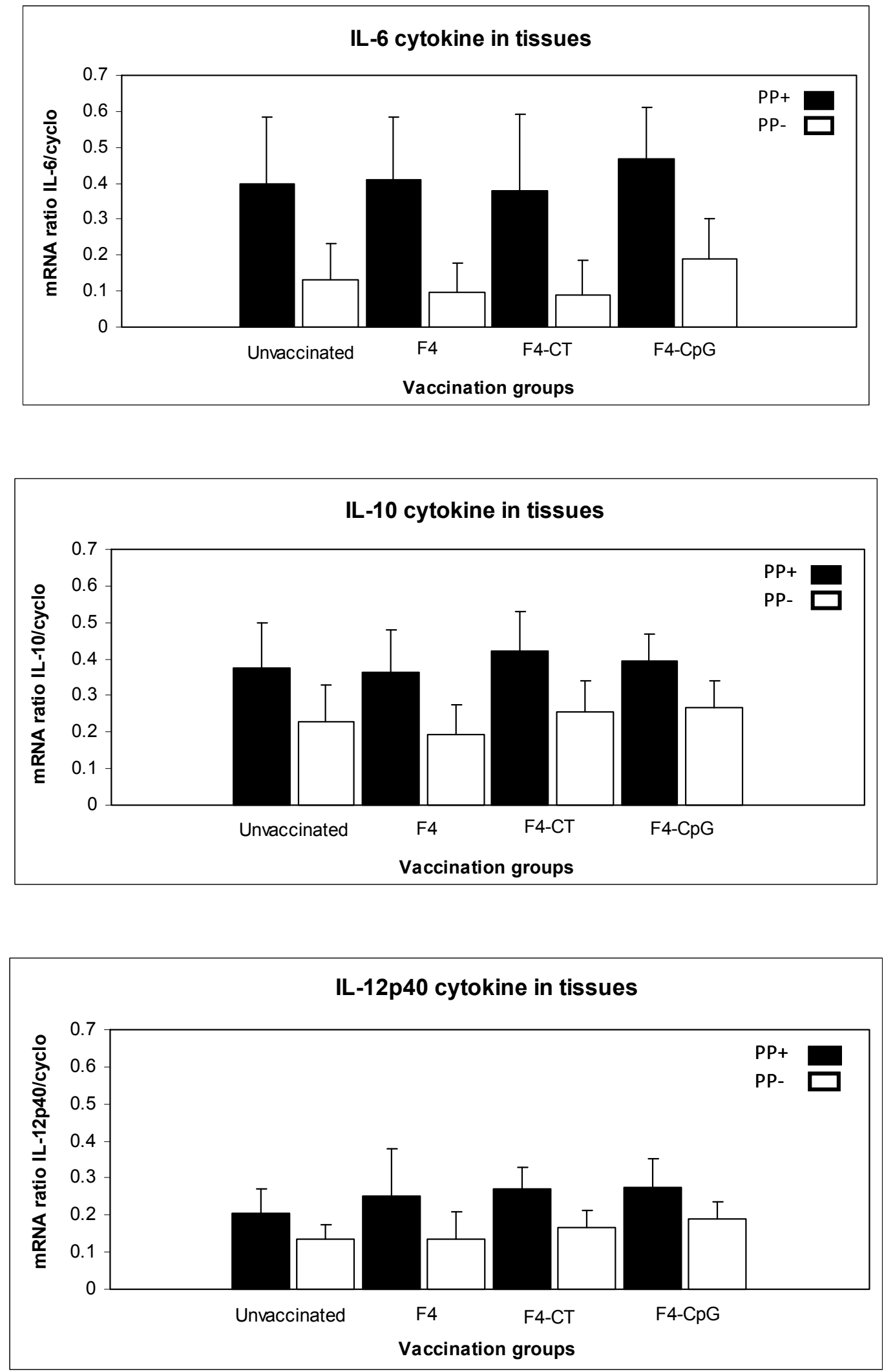


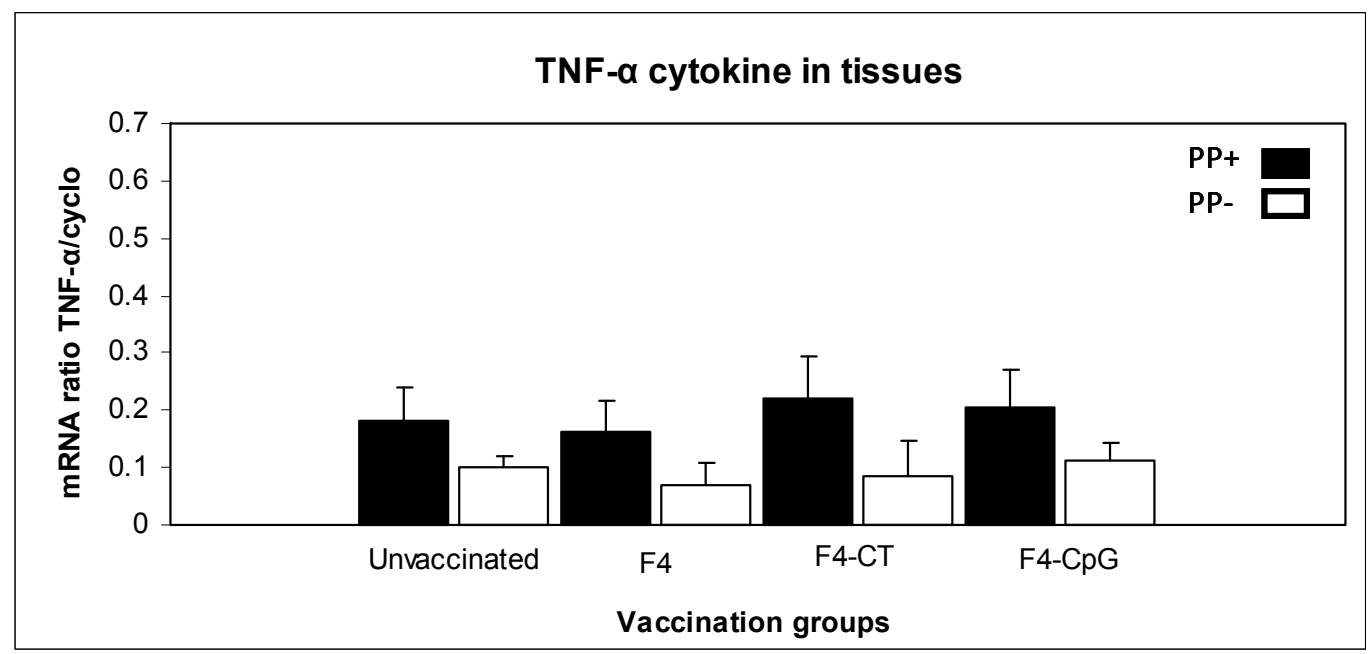

Figure 4. mRNA expression for cytokines IL-12p40, IL-6, IL-10 and TNF- $\alpha$ in intestinal tissues containing or lacking Peyer's patches (PP+ and PP- respectively) of pigs after oral administration of F4 fimbriae formulated with carboxymethyl high amylose starch (CMS) Unvaccinated group: CMS monolithic tablets $(200 \mathrm{mg})$. Vaccinated groups: CMS monolithic tablets $(200 \mathrm{mg}$ ) containing $500 \mu \mathrm{g}$ F4 fimbriae (F4 group), $500 \mu \mathrm{g}$ F4 fimbriae and $25 \mu \mathrm{g}$ complete cholera toxin (F4-CT group), $500 \mu \mathrm{g}$ F4 fimbriae and $50 \mu \mathrm{g}$ Cytosine-phosphate-Guanosine-Oligodeoxynucleotide (F4-CpG) group (n=5 $\mathrm{pigs} /$ group for vaccinated groups and $\mathrm{n}=7 \mathrm{pigs} /$ group for unvaccinated group). Degree of substitution of CMS: 0.157 .

For each cytokine, the amount of the RT-PCR product was normalized to the value of cyclophilin (cyclo), a constitutively expressed housekeeping gene used as standard for each sample.

\section{DISCUSSION}

CMS was proposed as an excipient where functionality depends on $\mathrm{pH}$ with the ability to protect $\mathrm{F} 4$ fimbriae in an oral vaccine against gastric acidity and pepsin, when formulated as monolithic tablet (9). Indeed, the F4 fimbriae formulated with CMS as monolithic tablets had a higher stability after incubation in simulated gastric fluid containing pepsin (32) than the non-protected F4 fimbriae, the latter being completely digested after 120 min of incubation (9). Moreover, the F4 fimbriae were liberated from CMS monolithic tablets during a period of up to $5 \mathrm{~h}$ of incubation in simulated intestinal fluid (32), a time interval that should be sufficient for F4 fimbriae to access F4specific intestinal sites in vivo conditions. The present in vivo study confirmed the ability of F4 fimbriae in a CMS formulation to reach the specific sites of action in the pig intestine and to stimulate a specific mucosal immune response.

Different studies showed that, before the immunisation procedure with F4 fimbriae in pigs, the gastric acidity has to be neutralized, in order to prevent possible alteration of fimbrial antigens during exposure to the gastric conditions. Sodium bicarbonate or other products, such as rabeprazolum, a proton pump inhibitor, are generally used to neutralize or to decrease the production of stomach acid (33-35). This strategy allowed oral immunization of pigs deprived of food and water $3 \mathrm{~h}$ before and $2 \mathrm{~h}$ after gastric $\mathrm{pH}$ neutralization and immunisation with F4 fimbriae (administered as a solution). It was shown by Snoeck et al. (33) that oral vaccination with F4 fimbriae formulated as enteric-coated pellets was beneficial compared to F4 fimbriae in solution since a good gastric protection of F4 fimbriae preserves the in vivo receptor binding activity. As the nonformulated F4 fimbriae are not stable enough in gastric conditions $(9,33)$, the in vivo oral administration of the CMS monolithic tablets containing $\mathrm{F} 4$ fimbriae can further improve vaccination. Furthermore, the CMS formulation does not need a coating material, making the processes of matrix fabrication simple and less expensive since the amount to administered is markedly lower than that required for free-flowing F4 vaccine.

A significant adjuvant effect of $\mathrm{CpG}$ was shown for the first time in this in vivo study when the 
adjuvant together with purified F4 fimbriae were formulated as monolithic tablets and orally administered to the pigs. This effect, manifested by an increased F4-specific IgM and IgG response in the intestinal contents, is beneficial for a vaccine designed to stimulate mucosal protection against the $\mathrm{F}^{+}$ETEC in pigs (5).

It has already been demonstrated that coadministration of a $\mathrm{CpG}$ with $\mathrm{F} 4$ fimbriae antigen to pigs by the parenteral route results in an increase of F4-stimulated PBMC proliferation in vitro and a reduction of faecal excretion of $\mathrm{F}^{+} E$. coli, although an effect on adaptive immunity was not shown (20). Our in vivo results complement well the in vitro data of Van der Stede et al. (19) who showed that CpG-A D19 induced $\mathrm{IgM}^{+}$B-cell activation and increased expression of MHC-II molecules in lymphocytes, in cultured swine PBMC. In addition, Zhang et al. (21) reported that parenteral administration of CpG-A D19 to newly weaned pigs significantly stimulated the proliferation of PBMC and the production of IFN- $\gamma$ in serum, thus enhancing the activation of the innate immune system.

The observation of a predominant $\operatorname{IgM}$ and $\operatorname{IgG}$ anti-F4 response in the present study is consistent with the relative antibody isotype response obtained in intestinal secretions of piglets in the first weeks of life (36). Snoeck et al. (8) showed a rapid and massive IgM response, as early as 14 days after intestinal immunization of pigs with F4 fimbriae, manifested by an increase in F4-specific IgM secreting cells in the $\mathrm{PP}+$ tissues. This rapid response would be particularly important in the early critical period of susceptibility to ETEC in pigs after weaning (37) and of rapid bacterial colonization of the intestines (4). Our results further confirm those of Snoeck et al. (8) who found IgG secreting cells in the gut associated lymphoid tissue after oral administration of F4 fimbriae and jejunum exposure to F4 fimbriae, mainly at 21 days postimmunization of pigs of 53-56 days of age. Even if specific anti-F4 mucosal IgG is not recognized as a major class of immunoglobulin involved in mucosal anti-F4 defence, in part because of its susceptibility to proteolytic degradation in gut secretions (38), it may still play an early role in IgA antibody affinity tuning (39). It may also play a role in passive paracellular transfer and cell surface scavenger sampling of luminal antigens (40).
The finding of a predominance of F4-specific IgM antibodies in the intestinal contents is also consistent with other similar studies $(34,41)$ of F4 oral immunization. Bianchi et al. (41) found that IgM is more commonly associated with mucosal sites in pigs than in other animal species and is the preferentially expressed immunoglobulin in the first 12 weeks of age in specific pathogen-free pigs. Our results are also consistent with the predominance of IgM antibodies in intestinal secretions observed following infection with live $\mathrm{F}^{+}$ETEC during early development of animals (36).

In our study, the absence of specific anti-F4 $\operatorname{Ig} \mathrm{A}$ in the intestinal contents 26 days after initial immunization is not consistent with previous data, suggesting a delayed production of IgA F4-specific antibodies. Verdonck et al. (34) noted that the $\operatorname{IgM}$ and $\operatorname{IgA}$ induction and the switching from $\operatorname{IgM}$ to IgA isotype were slower following oral immunization with purified F4 fimbriae than following $\mathrm{F}^{+}$ETEC infection (4, 34). Similarly, few specific anti-F4 IgA secreting cells were found in the jejunum and ileum 21 days after oral immunization of pigs with F4 fimbriae, in relation to the overall high level of IgM production at the same points in time (8).

We also examined cytokine expression in regions of the small intestine with $(+)$ or without (-) $\mathrm{PP}$ in an attempt to gain some insights into the mechanisms for the adjuvant effect of $\mathrm{CpG}$. An interesting finding was an up-regulation of the IFN$\gamma$ (Th1-type cytokine) and of the IL-6 (Th2-type cytokine), these being hallmark cytokines of antibody production. Similarly, Yi et al. (42) observed an increase of IL- 6 and, subsequently, of IgM antibodies in murine B cells stimulated with $\mathrm{CpG}$ and IFN- $\gamma$. Yamamoto et al. (43) reported that the production of IFN- $\gamma$ was itself induced in T cells by the presence of CpG. In other studies, stimulation with CpG-A D19 resulted in an increase of the expression of MHC-II in swine PBMC (44) and in B cells (19), an up-regulation of costimulatory factors CD80/CD86 (45) and a high production of IFN- $\alpha$, TNF- $\alpha$ and IL-12. The higher expression of Th1 cytokines, such as IFN- $\gamma$, IL-12, TNF- $\alpha$ and IL-1 $\beta$ observed in our study, is consistent with the up-regulation of cytokine mRNA expression observed in vitro and in vivo, following stimulation with the same CpG-A D19 compound $(16,17,21,45)$. All of these observations tend to indicate that oral 
administration of $\mathrm{CpG}$ - type A, particularly CpG-A D19, can stimulate innate and adaptive immune systems in pigs by generating a Th1/Th2 environment possibly involving both immune and non-immune cells in the intestinal mucosa. Our results fit well with other studies on $\mathrm{CpG}$ following parenteral administration or stimulation of immune cells in culture $(21,46,47)$. Surprisingly, although the expression of IL-4 was increased in intestinal tissues both containing and lacking PP, the overall expression of this cytokine was relatively low compared to that of other cytokines in our study. Parenteral injection of CpG D19 has been reported to have no effect on IL-4 production $(21,48)$. In addition, CpG D19 administration was associated with an inhibition of IL-4 production involved in allergic responses, although it enhanced IFN- $\gamma$ and IL-12 production (49) as reported in our study. The discrepancies concerning IL-4 production may be due to the different sites examined, various routes of vaccination or different experimental procedures used in these studies. The weak antibody and cytokine response following oral administration of F4 fimbriae alone underlines the need for an adjuvant to boost the humoral mucosal response. The difference between our results and those of Verdonck et al. (34), showing a significant anti-F4 antibody response following oral administration of F4 fimbriae without adjuvant, may be explained by the higher immunizing doses used in the latter study (2 mg fimbriae administered after the neutralization of acidic $\mathrm{pH}$ of the stomach). Other studies use even higher F4 fimbriae doses (4 mg fimbriae in PBS solution) to allow an optimal uptake of the antigen and to enhance the passage of unaltered ratio of fimbriae through the stomach (8). For different types of fimbriae (i.e. F18 fimbriae), even in the presence of a mucosal adjuvant, such as LT (R192G), higher doses of fimbriae (10 $\mathrm{mg}$ and, respectively, $30 \mathrm{mg}$ ) were used (50). Our combination of CpG-A D19 (50 $\mu \mathrm{g} /$ dosage form) with relatively small amounts of F4 $(500 \mu \mathrm{g}$ F4 fimbriae/dosage form) might provide a more costeffective way of stimulating anti-F4 antibody production. The relatively small amounts of F4 used in our study ( 8 fold less than that used by Snoeck et al. (8)) stimulated significantly higher levels of mucosal anti-F4 antibody in the presence of $\mathrm{CpG}$ adjuvant (F4-CpG group) than in its absence (F4 group). In addition, the ability of CMS matrix to protect the F4 fimbriae during the gastric transit and to deliver them to a specific absorption window probably contributed to the enhancement of this effect. Another beneficial effect of the CMS delivery system may be the resulting proximity between the F4 antigen and the adjuvant coformulated in the same tablet, this being a prerequisite for the efficacy of the $\mathrm{CpG}$ adjuvant when delivered to the antigen presenting cells (5152).

The lack of detectable specific anti-F4 antibodies in the sera of orally immunized pigs in our study may indicate that the systemic and small intestine mucosal responses are distinct when only the small intestine surface is exposed to F4 antigen. This may be due to differences in protein diffusion into villous capillaries, as hypothesized by Snoeck et al. (8) explaining lower serum specific antibody levels following colonic immunization with F4 fimbriae. In addition, since in other studies (5-7), F4 fimbriae were administered orally without a protecting and delivery system, it is possible that the immunogen would come into greater contact with pre-gut mucosal surfaces, such as buccal and laryngeal associated lymphoid tissues, thus generating a systemic antibody response. Another possible explanation for the lack of detectable serum anti-F4 antibodies observed in our study in the presence of adjuvants could be that the sows of the pigs used in our study had already been immunized with a commercial vaccine containing the F4 antigen.

Another surprising finding of our study was the lack of CT adjuvant effect on the mucosal antibody response to F4 fimbriae. This is unexpected, since complete $\mathrm{CT}$ is considered a potent mucosal adjuvant. Significantly higher salivary $\operatorname{IgA}$ and cellular F4 specific responses were observed following oral immunization of pigs with FaeG recombinant major adhesin of F4 (35) or with F4 fimbriae coupled to human serum albumin (53), when co-administered with CT. Furthermore, oral vaccination with non-replicating immunogens, such as subunit vaccines, has previously been associated with poor induction of serum antibodies $(8,54)$. A possible explanation for the decreased anti-F4 IgM levels when $\mathrm{CT}$ was co-administered with $\mathrm{F} 4$, could be a concomitant IgA isotype switching, as previously observed with CT (55). Our results are in agreement with data of Foss and Murtaugh (11) showing that the adjuvant effect of CT for heterologous proteins following oral administration 
was variable, with no induction of antibody response when CT was co-administered. Although no CT-associated adjuvant effect was observed on anti-F4 antibody response in our studies, the proinflammatory cytokine expression was nevertheless stimulated. In particular, IFN- $\gamma$ was up-regulated in both PP-containing and PP-lacking regions of the small intestine, suggesting that there was an inflammatory response and thus excluding the possibility of having provoked oral tolerance to $\mathrm{F} 4$ fimbriae by the immunization procedure. Oral immunization with $\mathrm{CT}$ in mice has been shown to influence protection against Helicobacter pylori through IL-18, a co-regulator of Th1 development associated with IFN- $\gamma$ production in gastric tissues (56). Similarly, Th1-type cytokine IL-18, as well as IFN- $\alpha$, were up-regulated in PP-lacking regions of the small intestine following co-administration of F4 fimbriae with $\mathrm{CT}$ in the present study. These findings provide more evidence of an immunomodulatory effect of $\mathrm{CT}$, being different from that observed for $\mathrm{CpG}$ adjuvant.

In conclusion, our results suggest a potential use of $\mathrm{CpG}$ as mucosal immune adjuvant for oral immunization with subunit vaccines, and underline the role of a Th1/Th2 cytokine balance in its adjuvant effects. CMS is a promising excipient for the formulation of monolithic tablets to be used for oral immunisation of pigs, due to its capacity to afford gastric protection for both the F4 fimbriae active agent and specific adjuvants, delivering fimbriae to their specific sites in the small intestine. Thus, the F4 fimbriae formulated with CMS excipient (monolithic tablets) can retain their receptor binding activity, an essential condition for the obtention of a mucosal immune response.

\section{Abbreviations}

CMS, Carboxymethyl High Amylose Starch; cyclo, cyclophilin; CpG-A D19, Cytosine-phosphateGuanosine-Oligodeoxynucleotide; CT, Cholera Toxin; $\mathrm{F}^{+}$ETEC, F4-positive Enterotoxigenic Escherichia coli; F4R, F4-specific Receptor; IFN, Interferon; Ig, Immunoglobulin; IL, Interleukin; MHC II, Major Histocompatibility Complex II; OD, Optical Density; PBMC, Peripheral Blood Mononuclear Cells; PBS, Phosphate Buffer Saline; PCR, Polymerase Chain Reaction; PP, Peyer's Patches; PWD, Post-Weaning Diarrhea; RT-PCR, Reverse Transcription Polymerase Chain Reaction; SDS-PAGE, Sodium Dodecyl Sulphate
Polyacrylamide Gel Electrophoresis; TNF, Tumour Necrosis Factor.

\section{ACKNOWLEDGMENTS}

This work was supported by grants from Valorisation Recherche Québec (VRQ), from the Research Group on Infectious Diseases of Swine (FQRNT, Quebec, Canada) and from Natural Sciences and Engineering Research Council of Canada (NSERC). We thank Brigitte Lehoux, Clarisse Desautels, Jade-Pascale Prévost Lemyre for technical assistance and Guy Beauchamp for statistical analysis.

\section{REFERENCES}

1. Fairbrother JM, Nadeau É, Gyles CL. Escherichia coli in postweaning diarrhea in pigs: an update on bacterial types, pathogenesis, and prevention strategies. Animal health research reviews / Conference of Research Workers in Animal Diseases, 2005; 6:17-39.

2. Van den Broeck W, Cox E, Oudega B, Goddeeris BM. The F4 fimbrial antigen of Escherichia coli and its receptors. Vet Microbiol, 2000; 71:223-244.

3. Freytag LC, Clements JD. Mucosal adjuvants. Vaccine, 2005; 23:1804-1813.

4. Verdonck F, Cox E, van Gog K, Van der Stede Y, Duchateau L, Deprez P, Goddeeris BM. Different kinetic of antibody responses following infection of newly weaned pigs with an F4 enterotoxigenic Escherichia coli strain or an F18 verotoxigenic Escherichia coli strain. Vaccine, 2002; 20:2995-3004.

5. Van den Broeck W, Cox E, Goddeeris BM. Induction of immune responses in pigs following oral administration of purified F4 fimbriae. Vaccine, 1999; 17:2020-2029.

6. Van den Broeck W, Cox E, Goddeeris BM. Receptordependent immune responses in pigs after oral immunization with F4 fimbriae. Infect Immun, 1999; 67:520-526.

7. Van den Broeck W, Bouchaut H, Cox E, Goddeeris BM. F4 receptor-independent priming of the systemic immune system of pigs by low oral doses of F4 fimbriae. Vet Immunol Immunopathol, 2002; 85:171178.

8. Snoeck V, Verfaillie T, Verdonck F, Goddeeris BM, Cox E. The jejunal Peyer's patches are the major inductive sites of the F4-specific immune response following intestinal immunisation of pigs with F4 (K88) fimbriae. Vaccine, 2006; 24:3812-3820.

9. Calinescu C, Nadeau É, Mulhbacher J, Fairbrother JM, Mateescu MA. Carboxymethyl high amylose starch for F4 fimbriae gastro-resistant oral formulation. Int $\mathrm{J}$ Pharm, 2007; 343:18-25.

10. Calinescu C, Mulhbacher J, Nadeau E, Fairbrother JM, Mateescu MA. Carboxymethyl high amylose starch 
(CM-HAS) as excipient for Escherichia coli oral formulations. Eur J Pharm Biopharm, 2005; 60:53-60.

11. Foss DL, Murtaugh MP. Mucosal immunogenicity and adjuvanticity of cholera toxin in swine. Vaccine, 1999; 17:788-801.

12. Lycke N, Bromander AK, Ekman L, Karlsson U, Holmgren J. Cellular basis of immunomodulation by cholera toxin in vitro with possible association to the adjuvant function in vivo. J Immunol, 1989; 142:20-27.

13. Lycke N. From toxin to adjuvant: the rational design of a vaccine adjuvant vector, CTA1-DD/ISCOM. Cell Microbiol, 2004; 6:23-32.

14. Murtaugh MP, Foss DL. Inflammatory cytokines and antigen presenting cell activation. Vet Immunol Immunopathol, 2002; 87:109-121.

15. Holmgren J, Adamsson J, Anjuere F, Clemens J, Czerkinsky C, Eriksson K, Flach CF, George-Chandy A, Harandi AM, Lebens M, Lehner T, Lindblad M, Nygren E, Raghavan S, Sanchez J, Stanford M, Sun JB, Svennerholm AM, Tengvall S. Mucosal adjuvants and anti-infection and anti-immunopathology vaccines based on cholera toxin, cholera toxin B subunit and CpG DNA. Immunol Lett, 2005; 97:181-188.

16. Kamstrup S, Verthelyi D, Klinman DM. Response of porcine peripheral blood mononuclear cells to CpGcontaining oligodeoxynucleotides. Vet Microbiol, 2001; 78:353-362.

17. Verfaillie T, Cox E, Goddeeris BM. Immunostimulatory capacity of DNA vaccine vectors in porcine PBMC: a specific role for CpG-motifs? Vet Immunol Immunopathol, 2005; 103:141-151.

18. Domeika K, Magnusson M, Eloranta ML, Fuxler L, Alm GV, Fossum C. Characteristics of oligodeoxyribonucleotides that induce interferon (IFN)alpha in the pig and the phenotype of the IFN-alpha producing cells. Vet Immunol Immunopathol, 2004; 101:87-102.

19. Van der Stede Y, Verdonck F, Verfaillie T, Goddeeris BM, Cox E. Porcine-specific CpGoligodeoxynucleotide activates B-cells and increases the expression of MHC-II molecules on lymphocytes. Vet Immunol Immunopathol, 2005; 105:115-124.

20. Van der Stede Y, Cox E, Verdonck F, Vancaeneghem $\mathrm{S}$, Goddeeris BM. Reduced faecal excretion of $\mathrm{F}^{+}-E$. coli by the intramuscular immunisation of suckling piglets by the addition of 1-alpha 2,5-dihydroxyvitamin D3 or CpG-oligodeoxynucleotides. Vaccine, 2003; 21:1023-1032.

21. Zhang $\mathrm{L}$, Tian $\mathrm{X}$, Zhou $\mathrm{F}$. In vivo effects of oligodeoxynucleotides containing synthetic immunostimulatory motifs in weaned piglets. Int Immunopharma, 2006; 6:1623-1631.

22. Levesque S, Martinez G, Fairbrother JM. Improvement of adjuvant systems to obtain a cost-effective production of high levels of specific IgY. Poultry Sci, 2007; 86:630-635.

23. Cadman E, Bostwick JR, Eichberg J. Determination of protein by Lowry procedure in the presence of some commonly used detergents. Anal Biochem, 1979; 96:21-23.
24. Broes A, Fairbrother JM, Lariviere S, Jacques M, Johnson WM. Virulence properties of enterotoxigenic Escherichia coli O8:KX105 strains isolated from diarrheic piglets. Infect Immun, 1988; 56:241-246.

25. Jensen GM, Frydendahl K, Svendsen O, Jorgensen CB, Cirera S, Fredholm M, Nielsen J-P, Moller K. Experimental infection with Escherichia coli O149:F4ac in weaned piglets. Vet Microbiol, 2006; 115:243-249.

26. Wenneras C, Qadri F, Bardhan PK, Sack RB, Svennerholm AM. Intestinal immune responses in patients infected with enterotoxigenic Escherichia coli and in vaccinees. Infect Immun, 1999; 67:6234-6241.

27. Morello CS, Ye M, Hung S, Kelley LA, Spector DH. Systemic priming-boosting immunization with a trivalent plasmid DNA and inactivated murine cytomegalovirus (MCMV) vaccine provides long-term protection against viral replication following systemic or mucosal MCMV challenge. J Virol, 2005; 79:159175.

28. Dozois CM, Oswald E, Gautier N, Serthelon JP, Fairbrother JM, Oswald IP. A reverse transcriptionpolymerase chain reaction method to analyze porcine cytokine gene expression. Vet Immunol Immunopathol, 1997; 58:287-300.

29. Solano-Aguilar GI, Zarlenga D, Beshah E, Vengroski K, Gasbarre L, Junker D, Cochran M, Weston C, Valencia D, Chiang C, Dawson H, Urban JF, Lunney JK. Limited effect of recombinant porcine interleukin12 on porcine lymphocytes due to a low level of IL-12 beta2 receptor. Vet Immunol Immunopathol, 2002; 89:133-148.

30. Pie S, Lalles JP, Blazy F, Laffitte J, Seve B, Oswald IP. Weaning is associated with an upregulation of expression of inflammatory cytokines in the intestine of piglets. J Nutr, 2004; 134:641-647.

31. Bensaude E, Turner JLE, Wakeley PR, Sweetman DA, Pardieu C, Drew TW, Wileman T, Powell PP. Classical swine fever virus induces proinflammatory cytokines and tissue factor expression and inhibits apoptosis and interferon synthesis during the establishment of longterm infection of porcine vascular endothelial cells. J Gen Virol, 2004; 85:1029-1037.

32. US Pharmacopeia XXII. US Pharmacopeial Convention, Rockville, MD, pp 1788-1789, 1990.

33. Snoeck V, Huyghebaert N, Cox E, Vermeire A, Vancaeneghem S, Remon JP, Goddeeris BM. Entericcoated pellets of F4 fimbriae for oral vaccination of suckling piglets against enterotoxigenic Escherichia coli infection. Vet Immunol Immunopathol, 2003; 96:219-227.

34. Verdonck F, Cox E, Van der Stede Y, Goddeeris BM. Oral immunization of piglets with recombinant $\mathrm{F} 4$ fimbrial adhesin FaeG monomers induces a mucosal and systemic F4-specific immune response. Vaccine, 2004; 22:4291-4299.

35. Verdonck F, Snoeck V, Goddeeris BM, Cox E. Cholera toxin improves the F4(K88)-specific immune response following oral immunization of pigs with recombinant FaeG. Vet Immunol Immunopathol, 2005; 103:21-29. 
36. Olsson E, Smyth CJ, Soderlind O, Svennerholm AM, Mollby R. Development of intestinal antibodies against Escherichia coli antigens in piglets with experimental neonatal E. coli diarrhoea. Vet Microbiol, 1986; 12:119-133.

37. Alexa P, Hamrik J, Stouracova K, Salajka E. Oral immunization against enterotoxigenic collibacillosis in weaned piglets by non-pathogenic Escherichia coli strain with K88 (F4) colonizing factor. Vet Med Czech, 2005; 50:5

38. Tizard, I., Veterinary Immunology: An introduction, $7^{\text {th }}$ edition. Philadelphia, Saunders, 2004.

39. Brandtzaeg P, Johansen FE. Mucosal B cells: phenotypic characteristics, transcriptional regulation, and homing properties. Immunol Rev, 2005; 206:3263.

40. Snoeck V, Peters IR, Cox E. The IgA system: a comparison of structure and function in different species. Vet Res, 2006; 37:455-467.

41. Bianchi AT, Scholten JW, Moonen Leusen BH, Boersma WJ. Development of the natural response of immunoglobulin secreting cells in the pig as a function of organ, age and housing. Dev Comp Immunol, 1999; 23:511-520.

42. Yi AK, Chace JH, Cowdery JS, Krieg AM. IFNgamma promotes IL-6 and IgM secretion in response to CpG motifs in bacterial DNA and oligodeoxynucleotides. J Immunol, 1996; 156:558-564.

43. Yamamoto S, Yamamoto T, Shimada S, Kuramoto E, Yano O, Kataoka T, Tokunaga T. DNA from bacteria, but not from vertebrates, induces interferons, activates natural killer cells and inhibits tumor growth. Microbiol Immunol, 1992; 36:983-997.

44. Linghua Z, Xingshan T, Fengzhen Z. In vivo effects of oligodeoxynucleotides containing synthetic immunostimulatory motifs in the immune response to swine streptococcic septicemia vaccine in weaned piglets. Mol Immunol, 2007; 44:1141-1149.

45. Guzylack-Piriou L, Balmelli C, McCullough KC, Summerfield A. Type-A CpG oligonucleotides activate exclusively porcine natural interferon-producing cells to secrete interferon-alpha, tumour necrosis factoralpha and interleukin-12. Immunology, 2004; 112:2837.
46. Linghua $\mathrm{Z}$, Xingshan $\mathrm{T}$, Fengzhen $\mathrm{Z}$. In vivo immunostimulatory effects of $\mathrm{CpG}$ ODN in newborn piglets. Mol Immunol, 2007; 44:1238-1244.

47. Vollmer J. CpG motifs to modulate innate and adaptive immune responses. Int Rev Immunol, 2006; 25:125134.

48. Zhang L, Tian X, Zhou F. CpG oligodeoxynucleotides augment the immune responses of piglets to swine Pasteurella multocida living vaccine in vivo. Res Vet Sci, 2007; 83:171-181.

49. Xu W, Tamura T, Takatsu K. CpG ODN mediated prevention from ovalbumin-induced anaphylaxis in mouse through B cell pathway. Int Immunopharm, 2008; 8:351-361.

50. Verdonck F, Tiels P, Van Gog K, Goddeeris BM, Lycke N, Clements J, Cox E. Mucosal immunisation of piglets with purified F18 fimbriae does not protect against F18+ Escherichia coli infection. Vet Immunol Immunopathol, 2007; 120:69-79.

51. Klinman DM, Currie D, Gursel I, Verthelyi D. Use of $\mathrm{CpG}$ oligodeoxynucleotides as immune adjuvants. Immunol Rev, 2004; 199:201-216.

52. Vajdy M, Srivastava I, Polo J, Donnelly J, O'Hagan D, Singh M. Mucosal adjuvants and delivery systems for protein-, DNA- and RNA-based vaccines. Immunol Cell Biol, 2004; 82:617-627.

53. Verdonck F, De Hauwere V, Bouckaert J, Goddeeris BM, Cox E. Fimbriae of enterotoxigenic Escherichia coli function as a mucosal carrier for a coupled heterologous antigen. J Control Release, 2005; 104:243-258.

54. Brandtzaeg P. Induction of secretory immunity and memory at mucosal surfaces. Vaccine, 2007; 25:54675484.

55. Lycke NY. Cholera toxin promotes B cell isotype switching by two different mechanisms. cAMP induction augments germ-line Ig H-chain RNA transcripts whereas membrane ganglioside GM1receptor binding enhances later events in differentiation. J Immunol, 1993; 150:4810-4821.

56. Akhiani AA, Schon K, Lycke N. Vaccine-induced immunity against Helicobacter pylori infection is impaired in IL-18-deficient mice. J Immunol, 2004; 173:3348-3356. 